\title{
Effects of Long-Term Fertilization on Organic Carbon and Nitrogen Dynamics in a Vertisol in Eastern China
}

\author{
Wei Li, Huan Chen, Chengfu Cao*, Zhu Zhao, Yuqiang Qiao, Shizhou Du \\ Crop Research Institute, Anhui Academy of Agricultural Sciences, Hefei, China \\ Email: *caocfu@126.com
}

How to cite this paper: $\mathrm{Li}, \mathrm{W}$., Chen, H., Cao, C.F., Zhao, Z., Qiao, Y.Q. and Du, S.Z. (2018) Effects of Long-Term Fertilization on Organic Carbon and Nitrogen Dynamics in a Vertisol in Eastern China. Open Journal of Soil Science, 8, 99-117. https://doi.org/10.4236/ojss.2018.83008

Received: January 25, 2018

Accepted: March 25, 2018

Published: March 28, 2018

Copyright ( 92018 by authors and Scientific Research Publishing Inc. This work is licensed under the Creative Commons Attribution International License (CC BY 4.0).

http://creativecommons.org/licenses/by/4.0/

\begin{abstract}
Mineral fertilizers and organic amendment can affect the various soil organic matter (SOM) pools and the distribution of organic carbon (OC) and nitrogen $(\mathrm{N})$ in these pools. It is unknown how $\mathrm{OC}$ and $\mathrm{N}$ are distributed in different SOM pools under different long-term fertilization regimes. Therefore, this study aimed to examine the effects on OC and $\mathrm{N}$ concentrations in various SOM pools after 33 years of application of chemical fertilizer and organic amendment in Anhui Province in the Huang-Huai-Hai Plain, eastern China. This long-term experiment consisted of five fertilization treatments measuring changes in the OC and $\mathrm{N}$ concentrations in the soils and different SOM fractions of each experiment plot. Organic amendment increased the $\mathrm{OC}$ and $\mathrm{N}$ concentrations in the mineral-associated fraction, the coarse mineral-associated fraction and the aggregates compared with the values obtained without fertilizer application. Mineral fertilizer application alone increased the abovementioned indexes, but this increase was small. There was a small but significant increase in the $\mathrm{OC}$ and $\mathrm{N}$ concentrations in the free particulate fraction, and the change in magnitude had no obvious effect on the total OC (TOC) and total $\mathrm{N}$ (TN) concentrations in soils. More than $80 \%$ of the water-stable aggregate-associated $\mathrm{C}$ was stored in macroaggregates $>2 \mathrm{~mm}$ in size. More than $60 \%$ of the TOC and TN accumulated within mineral associations in the soil, and organic amendment increased this proportion to $80 \%$. These results suggest that the OC in Vertisols is dominated by mineral-associated OC and that the effect of organic amendment on mineral-associated OC is obvious.
\end{abstract}

\section{Keywords}

Fertilization, Density Fractionation, Different Soil Organic Matter Fractions, Water-Stable Soil Aggregates, Vertisol 


\section{Introduction}

Soil organic matter (SOM) plays an important role in agroecosystem services [1] and crop yields [2] by maintaining and supplying nutrients to crops, forming soil aggregates and enhancing the water storage capacity. SOM is also closely related to soil physical, chemical, and biological properties [3]. The fertility and productivity of a soil are largely influenced by both the quantity and quality of SOM. Organic amendments are considered effective means for replenishing soil organic carbon (SOC) [2] [4]; this can result directly from C input to soils or indirectly from increased plant residue [5] and consequent changes in the quantity and quality of SOM. Nevertheless, the degree of response depends on climatic conditions, soil attributes, cropping system, amount and quality of organic input to soil, and intensity of disturbance induced by tillage.

Meanwhile, SOM is composed of various functional pools with different characteristics of stability and turnover, and the distribution of these pools is affected by soil management factors, such as crop rotation systems and fertilizer application [6]. Therefore, an analysis of the quantity and characteristics of these SOM pools is necessary to evaluate changes in soil fertility and SOM storage [7]. According to Marriott and Wander [8], the bulk SOC pool can be separated into conceptual aggregation fractions using a fractionation procedure based on different protection mechanisms. These separated fractions are called free particulate fraction (unprotected SOC inter-aggregate), occluded-microaggregate particulate fraction (or physically protected SOC) and mineral-associated fraction (chemically and biochemically protected SOC). In general, the particulate fraction is extracted by size, and the light fraction is separated by density [9]. The light fraction ( $>0.05 \mathrm{~mm}$ in size and $1.6-1.8 \mathrm{~g} \cdot \mathrm{cm}^{-3}$ in density) is an important component of the active OC pool and is considered to contain newly decomposing plant and animal residues with a rapid turnover unless it becomes protected by association with mineral particles [10]. The macro and light OM fractions are decomposed into smaller and finer OM fractions, which form the stabilized fraction with physical and/or chemical protection called the mineral-associated OM (MOM) and notably contribute to the total OC (TOC) [11]. This fraction is usually a recalcitrant OM pool due to it being protected with a slower turnover rate [7].

Many scholars have studied the SOC and nitrogen $(\mathrm{N})$ concentrations in Vertisols under different agricultural management practices. Wani et al. [12] reported increased SOC and total $\mathrm{N}(\mathrm{TN})$ under integrated land management to conserve soil and water combined with improved crop rotation. Chan [13] indicated that pools of SOC were lost during cropping on Vertisols in the semiarid subtropical area of Australia. Another study showed that cattle manure is a preferred method for enhancing SOC content in Vertisols in North China [14]. However, few studies have determined the effects of fertilization practices on SOM pools in Vertisols (order), particularly in aquic Vertisols (suborder). The Huang-Huai-Hai Plain constitutes approximately $16 \%$ of China's arable land 
and is a primary agricultural production area. Vertisols (specifically aquic Vertisols) are among the main soil types distributed in this important wheat-and maize-growing area. Vertisols in this area has a low SOM content $(<0.6 \%$ in the topsoil), a high clay content ( $>35 \%)$, and swelling and shrinking properties, which are conducive to self-mulching [15]. Agricultural sustainability is important in this region, and it is necessary to understand the characterization of SOM fractions and their dynamics. This study aimed to investigate the effects of the continuous application of mineral fertilizers and/or organic amendment alone and in combination at different rates on the OC and $\mathrm{N}$ concentrations in soils and in different fractions. The specific objectives were as follows: 1) to investigate the soil OC and $\mathrm{N}$ concentration changes in different SOM fractions under various long-term fertilizer regimes and 2) to determine the major organic $\mathrm{C}$ fractions that contribute to the increased TOC concentration.

\section{Materials and Methods}

\subsection{Description of the Study Site and Experimental Design}

This long-term field experiment was performed at the Agricultural Scientific Experimental Station, Huaibei City, Anhui Province, eastern China $\left(116^{\circ} 45^{\prime} \mathrm{N}\right.$, $\left.33^{\circ} 37^{\prime} \mathrm{E}\right)$. This area has a warm, temperate, humid monsoon climate with a mean annual precipitation of approximately $804 \mathrm{~mm}$ and an average annual temperature of $15.0^{\circ} \mathrm{C}$ (data from the Suixi Meteorological Station, 1981-2014). Precipitation shows strong inter-annual and seasonal variation, and approximately $70 \%$ of the annual precipitation occurs from May to September. The changes in rainfall and temperature in the area from the start of the experiment to the present are shown in Figure 1. The soil is a Vertisol according to US soil taxonomy (NRCS, USDA). According to the Chinese soil classification system [16] [17], the soil is an aquic Vertisol, which is the largest suborder of Vertisols in China.

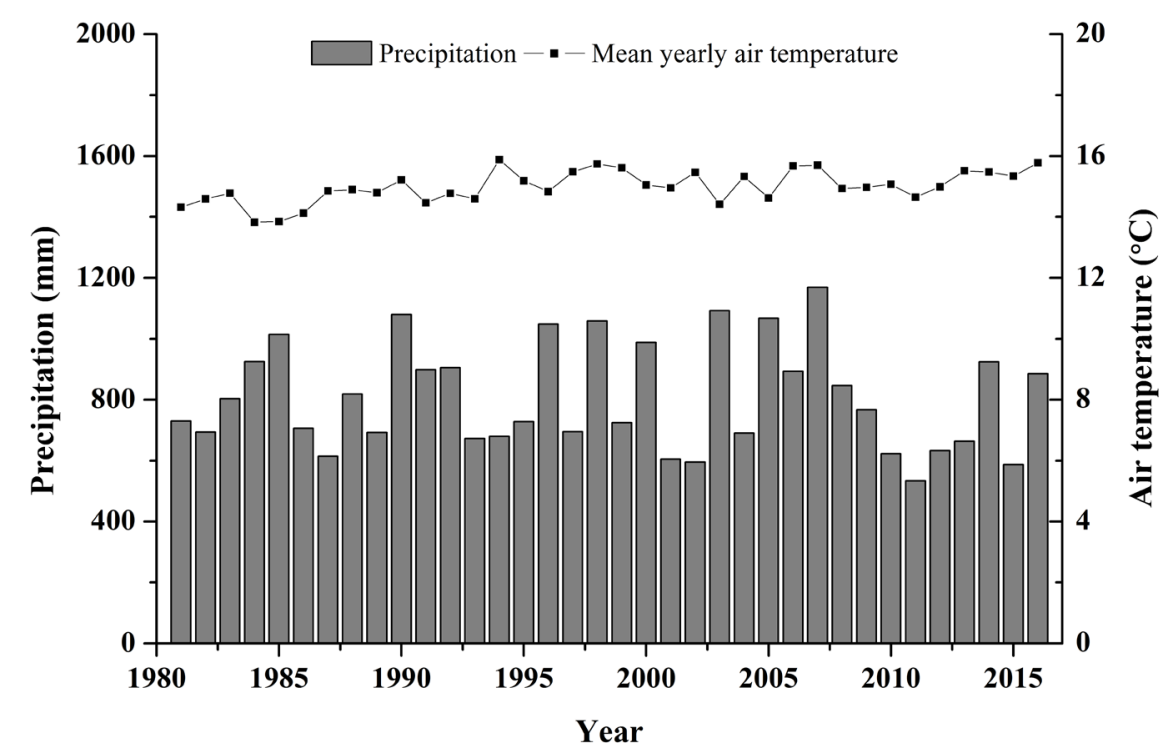

Figure 1. Local rainfall and temperature changes during the trial. 
Soil is developed predominantly in fluvial and lacustrine deposits [18]. The clay minerals in the soil are dominated by $2: 1$ montmorillonite. The soil $\mathrm{pH}$ ranges from 6.0 to 8.6 , and the SOC concentration ranges from 5.8 to $7.5 \mathrm{~g} \cdot \mathrm{kg}^{-1}$ at the experiment site. The topsoil under NPK (N-phosphorus-potassium) treatment after maize harvest in 2014 had a particle size distribution of $16.1 \pm 3.0 \mathrm{~g} \cdot \mathrm{kg}^{-1}$ coarse sand $(2-0.2 \mathrm{~mm}), 640.1 \pm 29.5 \mathrm{~g} \cdot \mathrm{kg}^{-1}$ fine sand $(0.2-0.02 \mathrm{~mm}), 53.8 \pm$ $5.2 \mathrm{~g} \cdot \mathrm{kg}^{-1}$ silt $(0.02-0.002 \mathrm{~mm})$ and $278.1 \pm 21.2 \mathrm{~g} \cdot \mathrm{kg}^{-1}$ clay $(<0.002 \mathrm{~mm})$; the soil texture was clay loam. The initial (1981) topsoil had $10.2 \mathrm{~g} \cdot \mathrm{kg}^{-1} \mathrm{TOC}, 0.78$ $\mathrm{g} \cdot \mathrm{kg}^{-1} \mathrm{TN}, 0.47 \mathrm{~g} \cdot \mathrm{kg}^{-1}$ total $\mathrm{P}, 64.1 \mathrm{mg} \cdot \mathrm{kg}^{-1}$ alkali-hydrolyzable $\mathrm{N}$, and 2.5 $\mathrm{mg} \cdot \mathrm{kg}^{-1}$ available $\mathrm{P}$. The crop rotation mode was wheat-soybean in 1981-1991 and in 1996-2006 and wheat-maize in 1992-1995 and from 2007 to the present. The long-term field experiment began in 1981 with five treatments: 1) control, no fertilizer (CK); 2) mineral NPK fertilizers alone (NPK); 3) organic amendment alone with $\mathrm{N}$ application rate equal to that of the NPK treatment (M);4) $50 \%$ of the $\mathrm{N}$ rate in the NPK treatment combined with $50 \%$ of the $\mathrm{N}$ rate in the $\mathrm{M}$ treatment (MNPK); and 5) $80 \%$ of the N rate in the NPK treatment combined with $80 \%$ of the $\mathrm{N}$ rate in the $\mathrm{M}$ treatment (hMNPK). The annual nutrient application rates are shown in Table 1 . From 1981 to 2003, the total seasonal mineral NPK fertilizers were urea, calcium superphosphate, and potassium chloride; from 2004 to the present, the mineral fertilizer used was compound fertilizer, which consisted of $\mathrm{N}-\mathrm{P}_{2} \mathrm{O}_{5}-\mathrm{K}_{2} \mathrm{O}$ (15-15-15). The application of mineral fertilizers accounted for $43 \%$ of the total seasonal mineral NPK fertilizers in the wheat season and $57 \%$ in the maize and soybean seasons.

Because the $\mathrm{N}, \mathrm{P}$ and $\mathrm{K}$ concentrations in compound fertilizer were equal (15-15-15), the amount of $\mathrm{N}$ applied in fertilization treatments was higher than that of $\mathrm{P}$ and $\mathrm{K}$ applied. Therefore, the amount of compound fertilizer was calculated according to the amount of $\mathrm{P}$ and $\mathrm{K}$ fertilizer, and the $\mathrm{N}$ deficiency was partly supplemented by urea for wheat. A total of $60 \%$ of the TN was applied at

Table 1. Mean application rates of mineral fertilizers and organic amendment for each treatment $\left(\mathrm{kg} \cdot \mathrm{ha}^{-1} \mathrm{yr}^{-1}\right)$.

\begin{tabular}{ccccccccccccc}
\hline \multirow{2}{*}{ Treatment } & \multicolumn{3}{c}{ Annual application rate } & \multicolumn{4}{c}{ Winter wheat } & \multicolumn{4}{c}{ Summer maize/Autumn grain } \\
\cline { 2 - 11 } & $\mathrm{N}$ & $\mathrm{P}_{2} \mathrm{O}_{5}$ & $\mathrm{~K}_{2} \mathrm{O}$ & $\mathrm{OM}$ & $\mathrm{N}$ & $\mathrm{P}_{2} \mathrm{O}_{5}$ & $\mathrm{~K}_{2} \mathrm{O}$ & $\mathrm{OM}$ & $\mathrm{N}$ & $\mathrm{P}_{2} \mathrm{O}_{5}$ & $\mathrm{~K}_{2} \mathrm{O}$ & $\mathrm{OM}$ \\
\hline $\mathrm{CK}$ & 0 & 0 & 0 & 0 & 0 & 0 & 0 & 0 & 0 & 0 & 0 & 0 \\
$\mathrm{NPK}$ & 525 & 210 & 210 & 0 & 225 & 105 & 105 & 0 & 300 & 105 & 105 & 0 \\
$\mathrm{M}$ & 0 & 0 & 0 & 525 & 0 & 0 & 0 & 525 & 0 & 0 & 0 & 0 \\
$\mathrm{MNPK}$ & 262.5 & 105 & 105 & 262.5 & 112.5 & 52.5 & 52.2 & 262.5 & 150 & 52.5 & 52.5 & 0 \\
hMNPK & 420 & 168 & 168 & 420 & 180 & 84 & 84 & 420 & 240 & 84 & 84 & 0 \\
\hline
\end{tabular}

Treatments were no fertilization (CK), mineral NPK fertilizers alone (NPK), organic manure alone (M), $50 \%$ of the nitrogen rate of the NPK treatment combined with $50 \%$ of the nitrogen rate of the M treatment (MNPK), and $80 \%$ of the nitrogen rate of the NPK treatment combined with $80 \%$ of the nitrogen rate of the $\mathrm{M}$ treatment (hMNPK). Organic amendment = fully-fermented soybean cake. Compound fertilizer was applied according to the amounts of total $\mathrm{P}$ and $\mathrm{K}$ before seeding for wheat and maize; the deficit of $\mathrm{N}$ fertilizer was compensated for by the application of urea. 
sowing and the remaining $\mathrm{N}$ as topdressing at the jointing stage in the wheat season, and $37.5 \%$ of the TN was applied at sowing and $62.5 \%$ as topdressing at the vegetative stage of the maize and soybean seasons. Organic amendment was fully fermented soybean cake and was applied before seeding as a base fertilizer during the wheat season. The amount of fully fermented soybean cake applied was calculated according to the $\mathrm{N}$ concentration of the cake. The physicochemical characteristics of fully fermented soybean cake were $100-150 \mathrm{~g} \cdot \mathrm{kg}^{-1}$ moisture, $300-400 \mathrm{~g} \cdot \mathrm{kg}^{-1} \mathrm{OM}$, and $60-70 \mathrm{~g} \cdot \mathrm{kg}^{-1} \mathrm{TN}$. The experiment had a completely randomized block spilt-plot design with four replications. Each plot was $40 \mathrm{~m}^{2}(5 \mathrm{~m} \times 8 \mathrm{~m})$ and was isolated by concrete plates $50 \mathrm{~cm}$ deep to prevent water and nutrients from flowing between plots. Crops were harvested by hand. Thus, stubble and roots in all plots were left in soils. All aboveground biomass was removed from the fields. The topsoil was shallow and tilled with a small rotocultivator before fertilization. Topdressing was performed in the afternoon, and sprinkler watering was performed immediately after fertilization in order to prevent the volatilization of $\mathrm{N}$.

\subsection{Soil Sampling and Analysis}

Soil samples were collected from the top $20 \mathrm{~cm}$ of each plot after maize harvest in October 2014. Samples were collected from seven locations in an S-shaped pattern in each plot using a soil core sampler with an inner diameter of $70 \mathrm{~mm}$. Subsequently, the samples were mixed into one composite sample, and visible pieces of crop residues and roots were removed. A total of 20 composite samples were taken to the laboratory. Soil samples were broken into $<10-\mathrm{mm}$ pieces by hand, air-dried at room temperature $\left(25^{\circ} \mathrm{C} \pm 0.5^{\circ} \mathrm{C}\right)$ and then sieved $(<2 \mathrm{~mm})$.

\subsection{Extraction of the MacroFraction}

The macro fraction was extracted using the method of Hai et al. [19]. The grouping method is shown in Figure 2. Double air-dried soil samples $(<2 \mathrm{~mm})$ of $20 \mathrm{~g}$ were placed in $250-\mathrm{ml}$ bottles with $100 \mathrm{ml}$ of $5 \% \mathrm{Na}$ hexametaphosphate solution overnight and then shaken on a shaking table at approximately $180 \mathrm{rpm}$ for $12 \mathrm{~h}$. The above process was carried out at room temperature. Two portions of the macro fraction $(>0.05 \mathrm{~mm})$ were obtained by wet sieving, and the soil suspension was repeatedly rinsed with distilled water until the scouring water was clean; the two portions were then oven-dried at $60^{\circ} \mathrm{C}$ and weighed. One macro fraction portion was used to determine the TOC and TN concentrations. The second portion was used to separate the heavy macro fraction using a centrifuge. An aliquot of $50 \mathrm{ml}$ of NaI solution with a density of $1.8 \mathrm{~g} \cdot \mathrm{cm}^{-3}$ was added to a $250-\mathrm{ml}$ centrifuge bottle containing the macro fraction, followed by shaking for $1 \mathrm{~h}$ on a vertical constant-temperature concussion incubator (Shanghai Mi-quan Instruments Co., Ltd., Model: MQL-61) at $180 \mathrm{rpm}$ to disperse the soil macro fraction. After standing overnight, the suspension was separated by centrifugation at $3000 \mathrm{~g}$ for $30 \mathrm{~min}$, and the suspended substances were poured off and discarded. The remnant in the centrifuge bottles was defined as the heavy macro fraction (density $>1.8 \mathrm{~g} \cdot \mathrm{cm}^{-3}$ ) [19]. After washing 


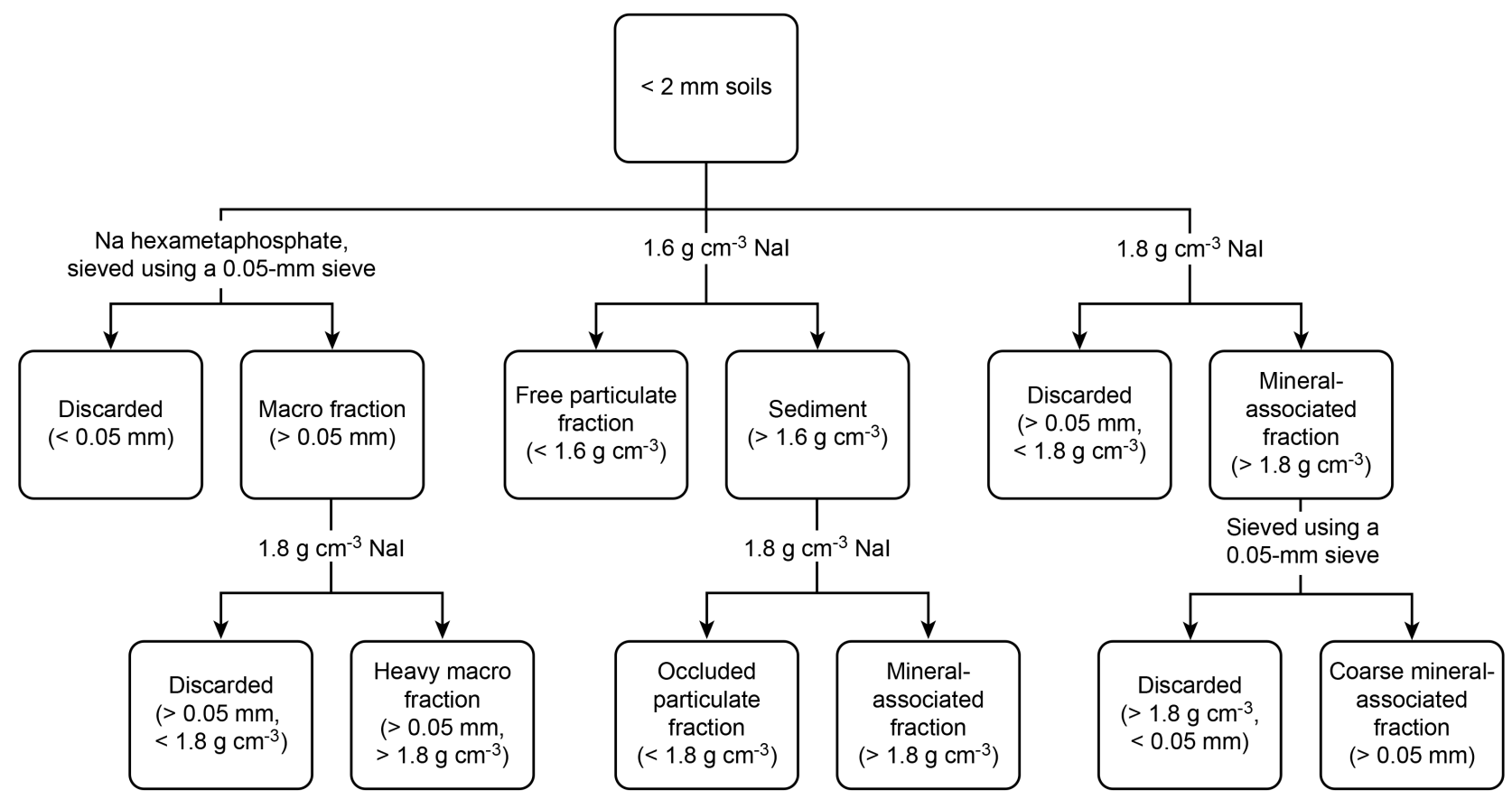

Figure 2. Fractionation procedures used to obtain macro fraction, heavy macro fraction, free particulate fraction, occluded particulate fraction, mineral-associated fraction, and coarse mineral-associated fraction from soils under different treatments. The light macro fraction was calculated by estimating the difference between the macro fraction and heavy macro fraction.

thrice with $50 \mathrm{ml}$ of distilled water and centrifuging to rinse the $\mathrm{NaI}$ residues, the macro fraction was collected, oven-dried at $60^{\circ} \mathrm{C}$ until a constant weight was achieved, weighed, and analyzed for the TOC and TN concentrations. The OC and $\mathrm{N}$ concentrations of the light macro fraction were determined by estimating the differences in the $\mathrm{OC}$ and $\mathrm{N}$ concentrations between the macro fraction and heavy macro fraction.

\subsection{Bulk Soil Fractionation by Density}

The grouping method using the density method of Hai et al. [19] is shown in Figure 2. Density fractionation was performed using NaI with two densities of $1.6 \mathrm{~g} \cdot \mathrm{cm}^{-3}$ and $1.8 \mathrm{~g} \cdot \mathrm{cm}^{-3}$. One air-dried soil sample of $20 \mathrm{~g}$ was placed in a $250-\mathrm{ml}$ centrifuge bottle together with $50 \mathrm{ml}$ of NaI with a density of $1.6 \mathrm{~g} \cdot \mathrm{cm}^{-3}$. The liquid was gently stirred on the vertical constant-temperature concussion incubator at $180 \mathrm{rpm}$ for $2 \mathrm{~min}$. The centrifuge bottle wall was rinsed with an additional $10 \mathrm{ml}$ of $\mathrm{NaI}$ to remove any adhering particles. After standing overnight, the liquid was centrifuged at $3000 \mathrm{~g}$ for $30 \mathrm{~min}$, and the supernatant was immediately filtered through a $0.45-\mu \mathrm{m}$ hydrophilic polyvinylidene fluoride filter (Ji'nan Xin well Medical Equipment Co., Ltd.) under vacuum. The material remaining on the filter, the free particulate fraction, was washed with distilled water until the water was clean. Aliquots of $50 \mathrm{ml}$ of NaI solution with a density of $1.8 \mathrm{~g} \cdot \mathrm{cm}^{-3}$ were added to the sediment in each centrifuge bottle $\left(>1.6 \mathrm{~g} \cdot \mathrm{cm}^{-3}\right)$ to re-suspend the particles, and the liquid was shaken on the vertical constant-temperature concussion incubator at $180 \mathrm{rpm}$ for $1 \mathrm{~h}$ to collect the oc- 
cluded particulate fraction $\left(<1.8 \mathrm{~g} \cdot \mathrm{cm}^{-3}\right)$. The pellet $\left(>1.8 \mathrm{~g} \cdot \mathrm{cm}^{-3}\right)$ remaining in the centrifuge bottle, which was defined as the mineral-associated fraction, was stirred and washed thrice with $50 \mathrm{ml}$ of $0.01 \mathrm{M} \mathrm{CaSO}_{4}$ solution and then thrice with distilled water, each time in combination with centrifugation. Then, the pellet was rinsed with distilled water and transferred from the centrifuge tube to the beaker.

Another air-dried soil sample of $20 \mathrm{~g}$ was placed in a $250-\mathrm{ml}$ centrifuge bottle together with $50 \mathrm{ml}$ of NaI with a density of $1.8 \mathrm{~g} \cdot \mathrm{cm}^{-3}$. The material was dispersed by horizontal shaking at $180 \mathrm{rpm}$ for $1 \mathrm{~h}$. After standing overnight, the mixed material was centrifuged at $3000 \mathrm{~g}$ for $30 \mathrm{~min}$; the suspended substance was poured off and discarded, and the remaining material in the centrifuge bottle was the mineral-associated fraction. The mineral-associated fraction was rinsed and sieved using a $0.05-\mathrm{mm}$-diameter sieve. The collected material was defined as the coarse mineral-associated fraction.

The extracted soil fractions were oven-dried at $60^{\circ} \mathrm{C}$ for $24 \mathrm{~h}$, weighed, ground by hand using a mortar and pestle and passed through a mesh screen with a 0.149 - $\mathrm{mm}$ diameter to obtain a fine powder to determine the OC and $\mathrm{N}$ concentrations.

\subsection{Separation of Water-Stable Soil Aggregates}

A modified wet-sieving method adapted from Elliott was used to separate the aggregation-size fractions in each sample [20]. A series of sieves with three different openings, $2 \mathrm{~mm}, 0.25 \mathrm{~mm}$, and $0.053 \mathrm{~mm}$, were used to separate three aggregate classes. A 100-g air-dried soil sample was placed on top of a 2-mm sieve and submerged for $5 \mathrm{~min}$ in distilled water at room temperature. The sieve was manually moved up and down $3 \mathrm{~cm}$ for a total of 50 times in 2 min to achieve complete separation of soil aggregates. At the end of the shock, aggregates left on the sieves with openings of $2 \mathrm{~mm}, 0.25 \mathrm{~mm}$, and $0.053 \mathrm{~mm}$ were collected (the corresponding water-stable soil aggregates classes were 1) large macroaggregates of $>2 \mathrm{~mm}$, 2) small macroaggregates of $0.25-2 \mathrm{~mm}$, and 3) microaggregates of $0.053-0.25 \mathrm{~mm}$ ), transferred into the beaker, oven-dried at $60^{\circ} \mathrm{C}$ for $24 \mathrm{~h}$ and weighed. The water-stable soil aggregates classes were obtained by the above methods.

\subsection{Determination of the SOC and N Concentrations}

The $\mathrm{C}$ concentration in soils and different soil fractions was determined by wet oxidation with $\mathrm{K}_{2} \mathrm{Cr}_{2} \mathrm{O}_{7}$ [21]. The $\mathrm{N}$ concentration was measured by semi-micro Kjeldahl digestion [21].

\subsection{Statistical Analysis}

ANOVA was performed to analyze the effects of the different fertilization treatments on the $\mathrm{C}$ and $\mathrm{N}$ concentrations in the soil fractions. Statistically significant differences were judged with the least significant difference (LSD) test at $p$ 
$<0.05$. Graphs were prepared using Origin Lab Pro 8.5. SPSS 16.0 (International Business Machines Corporation) was used for all statistical analyses.

\section{Results}

\subsection{Grain Yield}

The grain yield was significantly affected by different fertilization treatments (Figure 3 and Figure 4). In general, the maize grain yield was the highest, followed by wheat and soybean, among all treatments in all years (Figure 4). When averaged from 1982 to 2014, the annual grain yield followed the order hMNPK > MNPK > NPK > M > CK (Figure 3). The wheat yield of the M treatment was significantly $(p<0.05)$ lower than that of the NPK, MNPK and hMNPK treatments, but the yield gap in the M and NPK treatments decreased gradually until 2003; the yields of the MNPK and hMNPK treatments did not significantly differ in most years (Figure 4).

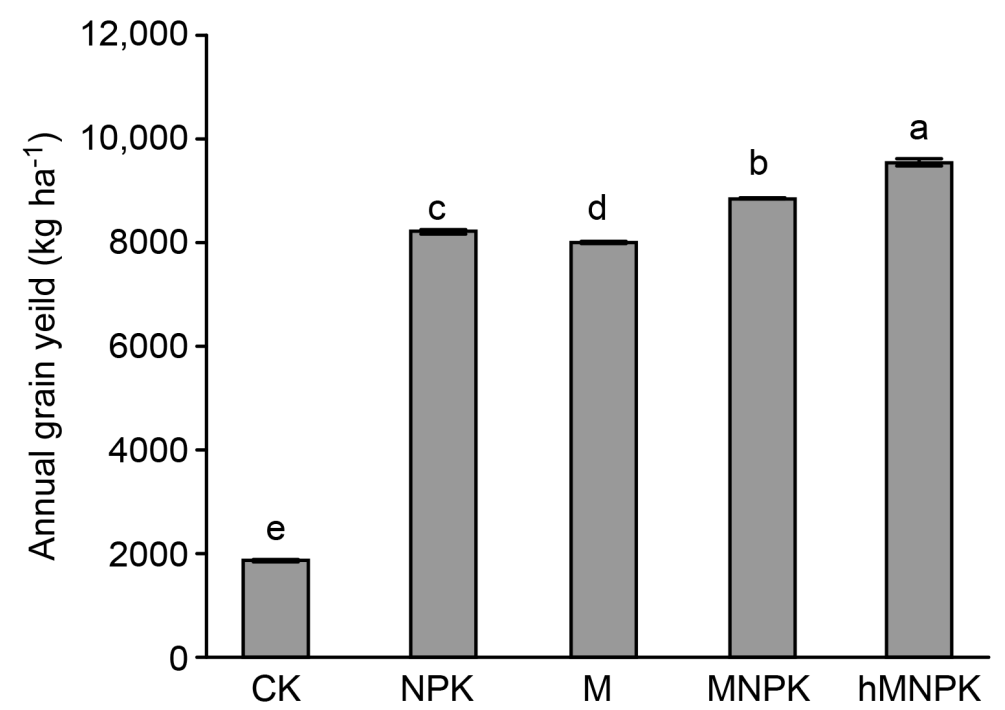

Figure 3. Mean annual grain yield under different fertilization treatments over 33 years. Error bars are the standard error of 4 replicates. Different small letters indicate significant differences at the 0.05 level according to the LSD multiple comparison.
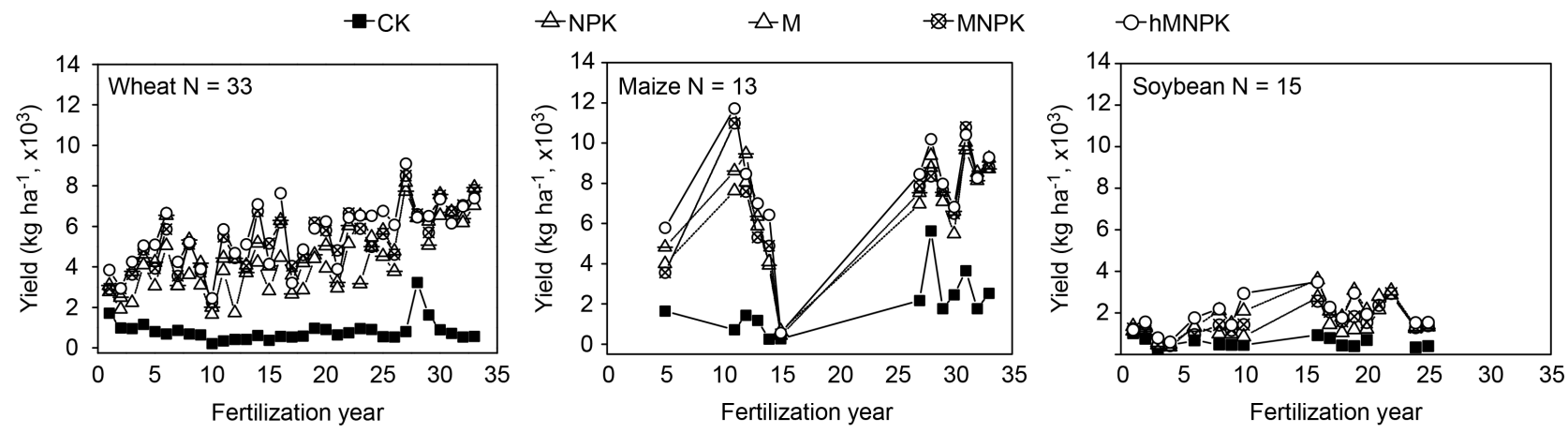

Figure 4. Dynamic changes in grain yields in five treatments from 1982 to 2014. 


\subsection{Total C and N}

Continuous mineral fertilizer application alone and its conjunction with organic amendment for 33 years significantly $(p<0.05)$ affected the TOC and TN concentrations (Table 2). Mineral fertilizer application alone increased the TOC and TN concentrations by $34 \%$ and $27 \%$, on average; however, increasing amplitudes of these concentrations under combined application of mineral fertilizer and organic amendment were greater, at 53\% - 83\% and $46 \%-62 \%$, respectively, especially under a high $\mathrm{N}$ rate (hMNPK). Compared with the sole application of mineral fertilizers, organic amendment increased the soil $\mathrm{C}$ and $\mathrm{N}$ concentrations by $14 \%-37 \%$ and $15 \%-31 \%$, respectively (Table 2 ).

\section{3. $\mathrm{C}$ and $\mathrm{N}$ in the Macro Fraction}

Mineral fertilizer application alone increased the $\mathrm{C}$ concentration of the macro fraction by $28 \%$ on average and the $\mathrm{C} / \mathrm{N}$ of the macro fraction by $25 \%$; however, the $\mathrm{N}$ concentration of the macro fraction was not affected by mineral fertilizers alone (Figure 5). In the M, MNPK and hMNPK treatments, the macro fraction OC concentration was affected by the mineral fertilizer and organic amendment application rate, which generally had small increments (Figure 5). However, only the hMNPK treatment created a significant difference compared with CK $(p<0.05)$, and its concentration increased by $21 \%$ and $16 \%$ compared with that in the M and MNPK treatments (Figure 5).

The OC and $\mathrm{N}$ concentrations of the heavy macrofraction hardly increased in any treatment (Figure 5). A higher $\mathrm{C} / \mathrm{N}$ ratio of the heavy macro fraction was observed with the combination of mineral fertilizer and organic amendment in the MNPK and hMNPK treatments, whereas a lower ratio was found after the application of mineral fertilizer alone (Figure 5). The OC concentration of the light macro fraction increased by $28 \%$ and $19 \%$ in the NPK and hMNPK treatments compared with that in the CK treatment. However, the $\mathrm{N}$ concentration of the light macro fraction in the fertilization treatments decreased by $7 \%$ on average compared with that in the CK treatment, regardless of whether mineral fertilizers were applied alone or in combination with organic amendment.

Table 2. TOC and $\mathrm{N}$ concentrations and $\mathrm{C} / \mathrm{N}$ ratio in different treatments.

\begin{tabular}{ccccc|}
\hline Sampling time & Treatment & Total organic C $\left(\mathrm{g} \cdot \mathrm{kg}^{-1}\right)$ & Total N $\left(\mathrm{g} \cdot \mathrm{kg}^{-1}\right)$ & $\mathrm{C} / \mathrm{N}$ \\
\hline 1981 & Initial & $5.93 \mathrm{e}$ & $0.78 \mathrm{e}$ & 7.6 \\
2014 & CK & $8.65 \pm 0.08 \mathrm{~d}$ & $1.08 \pm 0.01 \mathrm{~d}$ & 8.0 \\
& NPK & $11.60 \pm 0.26 \mathrm{c}$ & $1.37 \pm 0.01 \mathrm{c}$ & 8.5 \\
& M & $13.67 \pm 0.32 \mathrm{~b}$ & $1.79 \pm 0.02 \mathrm{a}$ & 7.6 \\
& MNPK & $13.27 \pm 0.39 \mathrm{~b}$ & $1.58 \pm 0.03 \mathrm{~b}$ & 8.4 \\
& hMNPK & $15.87 \pm 0.16 \mathrm{a}$ & $1.75 \pm 0.02 \mathrm{a}$ & 9.1 \\
\hline
\end{tabular}

CK, no fertilization; NPK, mineral NPK fertilizers alone; M, organic manure alone; MNPK, $50 \%$ of the nitrogen rate of the NPK treatment combined with $50 \%$ of the nitrogen rate of the M treatment; hMNPK, $80 \%$ of the nitrogen rate of the NPK treatment combined with $80 \%$ of the nitrogen rate of the M treatment. Organic manure, fully-fermented soybean cake manure. Different letters in the same column are significantly different $(p<0.05)$ among treatments according to LSD multiple comparisons. Data are presented as the mean \pm standard deviation. 


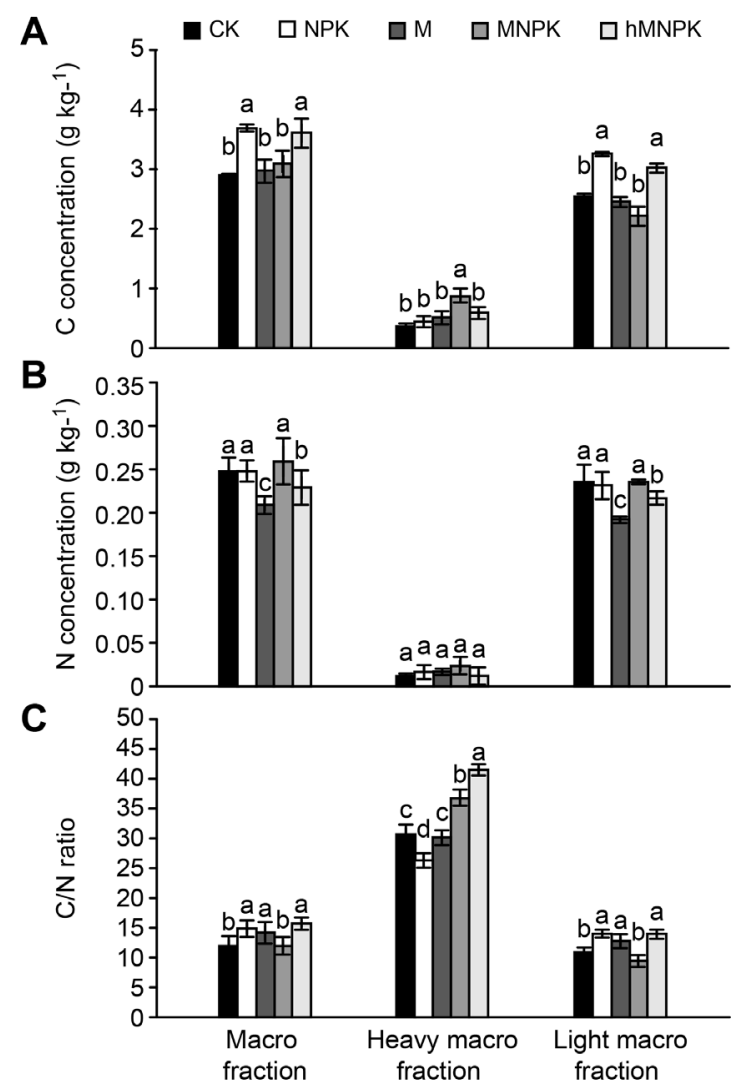

Figure 5. Organic $\mathrm{C}$ and $\mathrm{N}$ concentrations and the $\mathrm{C} / \mathrm{N}$ ratios of the macro fraction $(>0.05 \mathrm{~mm})$, heavy macro fraction (size $>0.05 \mathrm{~mm}$ and density $>1.8 \mathrm{~g} \cdot \mathrm{cm}^{-3}$ ) and light macro fraction (size $>0.05 \mathrm{~mm}$ and density $<1.8$ $\mathrm{g} \cdot \mathrm{cm}^{-3}$ ) in soils under different treatments. Error bars represent the standard error of 4 replicates. Different small letters in a group indicate significant differences at the 0.05 level according to the LSD multiple comparison.

\subsection{C and N in the Soil Density Fractions}

During the 33years of fertilization, the free particulate fraction $\left(<1.6 \mathrm{~g} \cdot \mathrm{cm}^{-3}\right.$ in density) had a mean $\mathrm{OC}$ concentration ranging from 0.16 to $0.21 \mathrm{~g} \mathrm{C} \mathrm{kg}^{-1}$ and an $\mathrm{N}$ concentration ranging from 0.015 to $0.018 \mathrm{~g} \mathrm{~N} \mathrm{~kg}^{-1}$; these values in the coarse mineral-associated fraction $\left(>1.8 \mathrm{~g} \cdot \mathrm{cm}^{-3}\right.$, and $\left.>0.05 \mathrm{~mm}\right)$ ranged from 1.54 to $2.77 \mathrm{~g} \cdot \mathrm{kg}^{-1}$ and 0.16 to $0.31 \mathrm{~g} \cdot \mathrm{kg}^{-1}$, respectively. The coarse mineral-associated C and $\mathrm{N}$ concentrations increased by $108 \%-133 \%$ and $155 \%-182 \%$, respectively, compared to those in the CK treatment; compared with those in the NPK treatment, these values were $60 \%-80 \%$ and $75 \%-94 \%$ (Table 3). However, the OC concentration in the occluded particulate fraction (1.6 - $1.8 \mathrm{~g} \cdot \mathrm{cm}^{-3}$ in density) slightly decreased by $3 \%-25 \%$, but the response of $\mathrm{N}$ was different. The occluded particulate $\mathrm{N}$ concentration increased by $5 \%-34 \%$ only under the combination of mineral fertilizer and organic amendment. In contrast, when either mineral fertilizer or organic amendment was applied alone, the occluded particulate $\mathrm{N}$ concentration decreased by $5 \%-29 \%$, especially after the sole applica- 
tion of mineral fertilizers. The $\mathrm{C} / \mathrm{N}$ ratio decreased when organic amendment was applied alone.

The mineral-associated fraction $\left(>1.8 \mathrm{~g} \cdot \mathrm{cm}^{-3}\right.$ in density) responded to fertilization by an obvious increase in the OC concentration of $84 \%-129 \%$ and in the $\mathrm{N}$ concentration of $65 \%-115 \%$ compared to the CK treatment (Table 3). In the treatments in which organic amendment was applied alone, the OC and $\mathrm{N}$ concentrations of the mineral-associated fraction increased by $12 \%-39 \%$ and $22 \%$ $30 \%$, respectively, compared to the NPK treatment (Table 3).

\subsection{Water-Stable Aggregate Fraction C and N}

Organic amendment application increased the OC concentration of the water-stable aggregate fraction from $26 \%$ to $43 \%$ and the $\mathrm{N}$ concentration from $17 \%$ to $33 \%$ for macroaggregates $>2 \mathrm{~mm}$ in size compared to CK (Table 4). For macroaggregates 0.25 - $2 \mathrm{~mm}$ in size, these increases were $42 \%-47 \%$ and $50 \%$, respectively, for $\mathrm{OC}$ and $\mathrm{TN}$ compared to $\mathrm{CK}$ (Table 4). For microaggregates

Table 3. Organic $\mathrm{C}$ and $\mathrm{N}$ concentrations and $\mathrm{C} / \mathrm{N}$ ratio of soil density fractions under different fertilizations.

\begin{tabular}{|c|c|c|c|c|c|c|c|c|c|c|c|c|}
\hline \multirow{2}{*}{ Treatment } & \multicolumn{3}{|c|}{ Free particulate fraction } & \multicolumn{3}{|c|}{ Occluded particulate fraction } & \multicolumn{3}{|c|}{ Mineral-associated fraction } & \multicolumn{3}{|c|}{ Coarse mineral-associated fraction } \\
\hline & $\mathrm{C}\left(\mathrm{g} \cdot \mathrm{kg}^{-1}\right)$ & $\mathrm{N}\left(\mathrm{g} \cdot \mathrm{kg}^{-1}\right)$ & $\mathrm{C} / \mathrm{N}$ & $\mathrm{C}\left(\mathrm{g} \cdot \mathrm{kg}^{-1}\right)$ & $\mathrm{N}\left(\mathrm{g} \cdot \mathrm{kg}^{-1}\right)$ & $\mathrm{C} / \mathrm{N}$ & $\mathrm{C}\left(\mathrm{g} \cdot \mathrm{kg}^{-1}\right)$ & $\mathrm{N}\left(\mathrm{g} \cdot \mathrm{kg}^{-1}\right)$ & $\mathrm{C} / \mathrm{N}$ & $\mathrm{C}\left(\mathrm{g} \cdot \mathrm{kg}^{-1}\right)$ & $\mathrm{N}\left(\mathrm{g} \cdot \mathrm{kg}^{-1}\right)$ & $\mathrm{C} / \mathrm{N}$ \\
\hline CK & $0.13 \pm 0.00 \mathrm{~d}$ & $0.009 \pm 0 \mathrm{c}$ & 15 & $2.88 \pm 0.0 \mathrm{a}$ & $0.38 \pm 0.01 b$ & 7.5 & $5.63 \pm 0.1 \mathrm{~d}$ & $0.62 \pm 0.01 \mathrm{c}$ & 9.1 & $1.19 \pm 0.00 \mathrm{c}$ & $0.11 \pm 0.00 \mathrm{~d}$ & 10.7 \\
\hline NPK & $0.20 \pm 0.01 \mathrm{a}$ & $0.015 \pm 0 \mathrm{~b}$ & 13 & $2.16 \pm 0.1 \mathrm{c}$ & $0.27 \pm 0.00 \mathrm{c}$ & 7.9 & $9.24 \pm 0.1 \mathrm{c}$ & $1.02 \pm 0.01 \mathrm{~b}$ & 9.1 & $1.54 \pm 0.00 \mathrm{~b}$ & $0.16 \pm 0.01 \mathrm{c}$ & 9.9 \\
\hline M & $0.16 \pm 0.01 \mathrm{c}$ & $0.018 \pm 0 \mathrm{a}$ & 9 & $2.30 \pm 0.1 b$ & $0.36 \pm 0.01 b$ & 6.4 & $12.19 \pm 0.2 \mathrm{a}$ & $1.24 \pm 0.01 \mathrm{a}$ & 9.8 & $2.57 \pm 0.01 \mathrm{a}$ & $0.29 \pm 0.01 \mathrm{a}$ & 8.8 \\
\hline MNPK & $0.18 \pm 0.01 \mathrm{~b}$ & $0.018 \pm 0 \mathrm{a}$ & 10 & $2.73 \pm 0.1 \mathrm{a}$ & $0.40 \pm 0.00 \mathrm{~b}$ & 6.8 & $10.36 \pm 0.1 \mathrm{~b}$ & $1.02 \pm 0.00 \mathrm{~b}$ & 10.2 & $2.47 \pm 0.00 \mathrm{ab}$ & $0.28 \pm 0.01 \mathrm{a}$ & 8.8 \\
\hline hMNPK & $0.21 \pm 0.00 \mathrm{a}$ & $0.018 \pm 0 \mathrm{a}$ & 11 & $2.79 \pm 0.1 \mathrm{a}$ & $0.51 \pm 0.00 \mathrm{a}$ & 6.9 & $12.88 \pm 0.1 \mathrm{a}$ & $1.33 \pm 0.00 \mathrm{a}$ & 9.7 & $2.77 \pm 0.00 \mathrm{a}$ & $0.31 \pm 0.01 \mathrm{a}$ & 8.9 \\
\hline
\end{tabular}

CK, no fertilization; NPK, mineral NPK fertilizers alone; M, organic manure alone; MNPK, $50 \%$ of the nitrogen rate of the NPK treatment combined with $50 \%$ of the nitrogen rate of the M treatment; hMNPK, $80 \%$ of the nitrogen rate of the NPK treatment combined with $80 \%$ of the nitrogen rate of the M treatment. Organic manure, fully-fermented soybean cake. Different letters in the same column are significantly different $(p<0.05)$ among treatments according to LSD multiple comparisons. Data are presented as the mean \pm standard deviation.

Table 4. Organic $\mathrm{C}$ and $\mathrm{N}$ concentrations in the water-stable aggregates.

\begin{tabular}{cccccccccc}
\hline \multirow{2}{*}{ Treatment } & \multicolumn{3}{c}{$>2 \mathrm{~mm}$} & \multicolumn{3}{c}{$0.25-2 \mathrm{~mm}$} & & \multicolumn{2}{c}{$0.05-0.25 \mathrm{~mm}$} \\
\cline { 2 - 9 } & $\mathrm{C}\left(\mathrm{g} \cdot \mathrm{kg}^{-1}\right)$ & $\mathrm{N}\left(\mathrm{g} \cdot \mathrm{kg}^{-1}\right)$ & $\mathrm{C} / \mathrm{N}$ & $\mathrm{C}\left(\mathrm{g} \cdot \mathrm{kg}^{-1}\right)$ & $\mathrm{N}\left(\mathrm{g} \cdot \mathrm{kg}^{-1}\right)$ & $\mathrm{C} / \mathrm{N}$ & $\mathrm{C}\left(\mathrm{g} \cdot \mathrm{kg}^{-1}\right)$ & $\mathrm{N}\left(\mathrm{g} \cdot \mathrm{kg}^{-1}\right)$ & $\mathrm{C} / \mathrm{N}$ \\
\hline $\mathrm{CK}$ & $0.35 \pm 0.01 \mathrm{~d}$ & $0.06 \pm 0.000 \mathrm{c}$ & 6.08 & $0.36 \pm 0.02 \mathrm{~b}$ & $0.06 \pm 0.000 \mathrm{~b}$ & 5.79 & $0.07 \pm 0.00 \mathrm{c}$ & $0.01 \pm 0.00 \mathrm{c}$ & 5.57 \\
$\mathrm{NPK}$ & $0.41 \pm 0.01 \mathrm{c}$ & $0.07 \pm 0.000 \mathrm{~b}$ & 6.16 & $0.38 \pm 0.02 \mathrm{~b}$ & $0.07 \pm 0.000 \mathrm{~b}$ & 5.05 & $0.10 \pm 0.00 \mathrm{~b}$ & $0.02 \pm 0.00 \mathrm{~b}$ & 5.37 \\
$\mathrm{M}$ & $0.45 \pm 0.02 \mathrm{~b}$ & $0.07 \pm 0.000 \mathrm{~b}$ & 6.04 & $0.52 \pm 0.01 \mathrm{a}$ & $0.09 \pm 0.001 \mathrm{a}$ & 5.72 & $0.14 \pm 0.01 \mathrm{a}$ & $0.03 \pm 0.00 \mathrm{a}$ & 4.41 \\
$\mathrm{MNPK}$ & $0.44 \pm 0.02 \mathrm{~b}$ & $0.08 \pm 0.001 \mathrm{a}$ & 5.84 & $0.51 \pm 0.01 \mathrm{a}$ & $0.09 \pm 0.001 \mathrm{a}$ & 5.84 & $0.14 \pm 0.01 \mathrm{a}$ & $0.02 \pm 0.00 \mathrm{~b}$ & 6.64 \\
$\mathrm{hMNPK}$ & $0.50 \pm 0.01 \mathrm{a}$ & $0.08 \pm 0.001 \mathrm{a}$ & 6.26 & $0.51 \pm 0.01 \mathrm{a}$ & $0.09 \pm 0.001 \mathrm{a}$ & 5.61 & $0.16 \pm 0.01 \mathrm{a}$ & $0.03 \pm 0.00 \mathrm{a}$ & 6.14 \\
\hline
\end{tabular}

CK, no fertilization; NPK, mineral NPK fertilizers alone; M, organic manure alone; MNPK, 50\% of the nitrogen rate of the NPK treatment combined with $50 \%$ of the nitrogen rate of the M treatment; hMNPK, $80 \%$ of the nitrogen rate of the NPK treatment combined with $80 \%$ of the nitrogen rate of the M treatment. Organic manure, fully-fermented soybean cake. Different letters in the same column are significantly different $(p<0.05)$ among treatments according to LSD multiple comparisons. Data are presented as the mean \pm standard deviation. 
$0.05-0.25 \mathrm{~mm}$ in size, these increases were $100 \%-129 \%$ and $100 \%-200 \%$, respectively, compared to CK (Table 4). Compared with NPK treatment, the OC and TN concentrations from organic amendment increased by $7 \%-22 \%$ and $14 \%$, 34\% - 37\% and 29\%, and $40 \%-60 \%$ and $50 \%$, respectively for the $\mathrm{M}$, MNPK and hMNPK treatments. The OC and TN concentrations in different aggregates were significantly higher under organic amendment than those in the NPK treatments. Higher OC and N concentrations accumulated in macroaggregates $(>0.25 \mathrm{~mm}$ in size) than in microaggregates $(0.05-0.25 \mathrm{~mm}$ in size) (Table 4).

\subsection{Relationship among the Different Organic Fractions}

There was a positive correlation between TOC and coarse mineral-associated OC $(R=0.92, p<0.001)$ as well as mineral-associated OC $(R=0.91, p<0.001)$ (Figure 6). The correlations between the TN and the coarse mineral-associated $\mathrm{N}$, mineral-associated $\mathrm{N}$ and free particulate $\mathrm{N}$ were consistent with those with the SOC $(R=0.92, p<0.001 ; R=0.94, p<0.001 ; R=0.96, p<0.001$, respectively) (Figure 6). Correlation analysis revealed that the coarse mineral-associated fraction and mineral-associated fraction played significant roles in increasing the total SOM.

\section{Discussion}

\subsection{Soil C and $N$}

In our study, the TOC concentration significantly $(p<0.05)$ increased by $84 \%$ after a 33-year integrated application of mineral fertilizers with organic amendment (hMNPK) compared to that under the CK treatment; however, the corresponding values were 58\%,53\%, and 34\% for the M, MNPK, and NPK treatments, respectively. Hai et al. [19] reported that farmland manure alone and its combination with NPK in the wheat-corn production system characterized by straw removal and conventional tillage in semiarid and arid regions increased the mean TOC concentration by $43 \%$ compared to that in CK plots where farmland manure was absent. Ding et al. [22] found that a Mollisol amended with mineral fertilizers plus pig manure (NPKM) contained a 7\% higher TOC concentration than that under NPK treatment at the $0-15 \mathrm{~cm}$ depth after 21 years of application. Research of a Vertisol of central India showed that the SOC content in $100 \%$ NPK + farmyard manure (FYM) treatments increased by $56.3 \%$ over the initial level [23].Other long-term experiments conducted elsewhere revealed similar effects of organic amendment on TOC concentration [24] [25]. Organic amendment generally favors soil aggregation to physically protect fractions against decomposition better than do crop roots and residues, and these effects result in an increase in the TOC concentration [2]. The highest TOC concentration in hMNPK soils could also be attributed to the improved structure as a result of long-term organic addition due to a higher humification coefficient of the organic substances added to soil than that of the crop roots and residues in soil [26]. However, the effect of mineral fertilizers on increasing the 

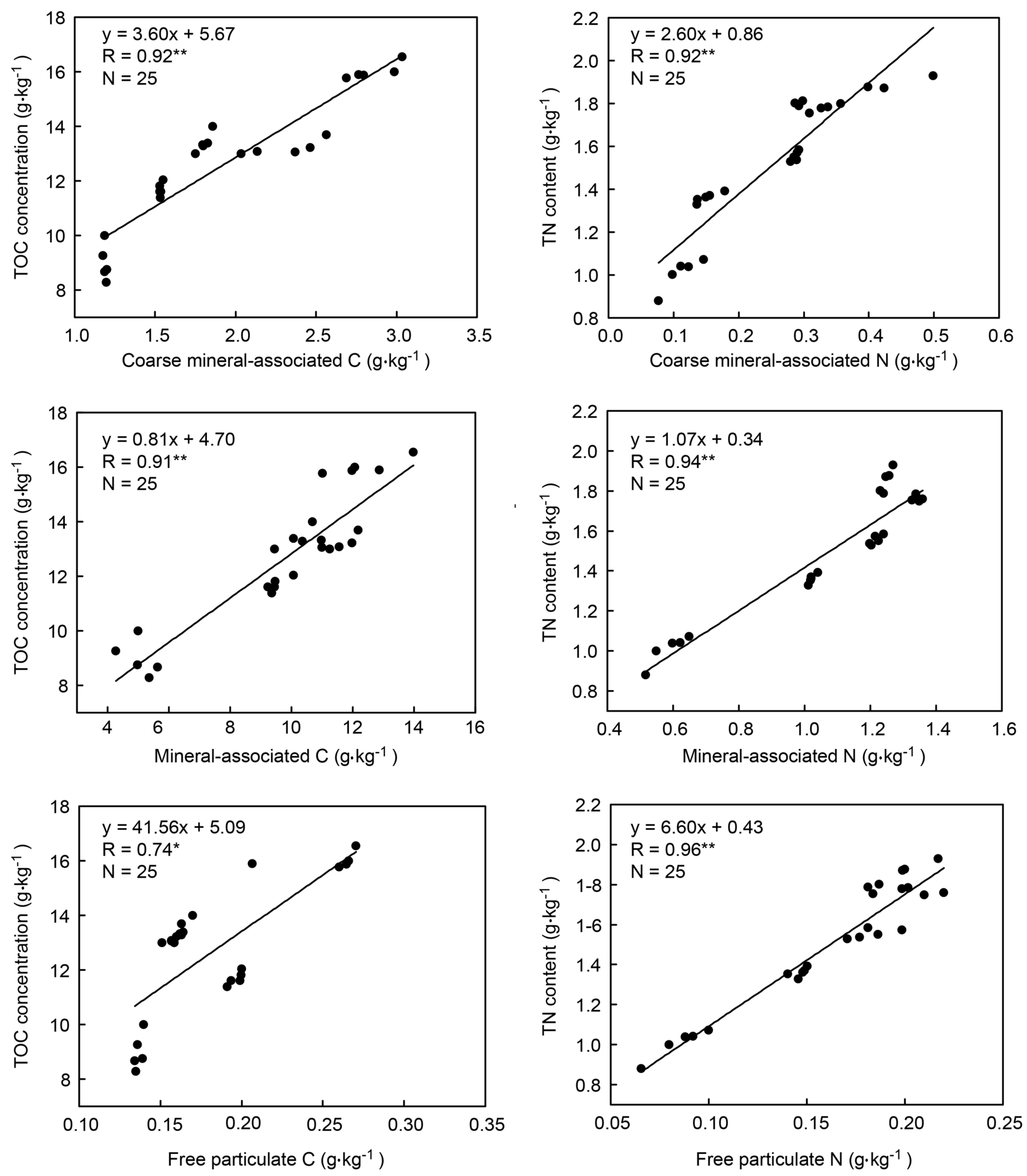

Figure 6. Analysis of the relationship between $\mathrm{C}$ and $\mathrm{N}$ in soils and in the coarse mineral-associated, mineral-associated and free particulate fractions. ${ }^{*}$ indicates an extremely significant correlation; ${ }^{*}$ indicates a significant correlation.

TOC concentration is in dispute. Very little influence of $\mathrm{N}$ rate $\left(100 \mathrm{~kg} \mathrm{~N} \mathrm{ha}^{-1}\right)$ on SOC was observed in a Mediterranean Vertisol [27]. However, for a Vertisol in central India, the SOC content in the $100 \%$ NPK treatment increased by $23 \%$ [23]. The different conclusions concerning the impact of mineral fertilizers on 
TOC concentration may be related to the application rates of fertilizers, soil features at different experimental sites, initial concentrations, and diverse cropping systems. The present results are consistent with those from other studies [28] and indicate that a mixture of mineral fertilizers and organic amendment in a certain proportion is important for maintaining or increasing OC content in agricultural soils.

The TN concentration might significantly accumulate if only fertilizer is added to the soil due to increasing plant biomass production and $\mathrm{C}$ return to the soil [29]. Zhang et al. [30] reported that the TN concentration in red soil under CK, NP, PK, NPK, and NPKS treatments decreased after 16 years. Sekhon et al. [31] also noted a decrease in the soil TN concentration by $21.3 \%$ without any fertilization in rice-wheat cropping compared with the initial status in surface soil. Similar reports of a decrease in the soil TN concentration under no fertilization have been noted [32]. A significant increase in the soil TN concentration was observed under NPK and CK treatments. This increase agrees with the results in yellow brown soils [33] and might be caused by crop roots and stubble returning to the field over time after the last season's crop harvest. The greatest increase occurred under the M, MNPK, and hMNPK treatments that received organic amendment. These data suggest that despite the input of $\mathrm{N}$ in fertilization treatments, the accumulation of N in the soil was lower in the NPK plots than in the plots with organic amendment. This result could be due to the much slower release of $\mathrm{N}$ from the combination of NPK fertilizers and organic amendment than that from mineral NPK fertilizers alone, resulting in smaller losses of $\mathrm{N}$ and the accumulation of higher concentrations of soil TN.

\subsection{C and N Concentrations in Different Physical Fractions}

According to a combination of particle size and density fractionations, soil macrofraction C showed a slight tendency to increase under the NPK and hMNPK treatments, in contrast to the other treatments (Figure 5). This indicates that mineral fertilizers increase the soil macro fraction OC concentration mainly because the soil macro fraction $\mathrm{OC}$ is a transitional organic $\mathrm{C}$ pool between fresh animal and plant residues and humus. Concentration change is directly affected by residual roots and aspects of litter decomposition and mineralization. The light macro fraction is closely associated with microbial growth and nutrients [34] and is free from sand and sand-sized aggregates. This suggests that the light macro fraction is active and not protected by association with mineral particles; however, it is easily affected by soluble plant residue or soil microbial exudate. Consequently, this pool has a very short residence time. In the current study, the ratio of the heavy macro fraction to the light macro fraction ranged from $13.4 \%$ in NPK to $39.8 \%$ in MNPK for C and from $4.9 \%$ in CK to $10.1 \%$ in MNPK for N. These results showed that mineral fertilizer application is helpful for the formation of the soil light macro fraction and that the application of organic amendment is beneficial for the adsorption of the light macro fraction by soil minerals, which would lead to an increase in the heavy macro fraction. Heavy macro frac- 
tion data in Figure 5 also corroborate the above statements.

Clear increasing trends for the $\mathrm{OC}$ and $\mathrm{N}$ concentrations in the free particulate fraction under fertilization were found, and the maximum rates of increase were $62 \%$ for OC and $100 \%$ for $\mathrm{N}$ in the hMNPK treatment compared with $\mathrm{CK}$. Nevertheless, the magnitude of change in the free particulate fraction was still very small and did not significantly enhance the TOC or TN concentration. However, mineral fertilizers and organic amendment alone or in combination significantly $(p<0.05)$ decreased the OC concentration in the occluded particulate fraction compared with the $\mathrm{CK}$, and its $\mathrm{N}$ concentration increased under the MNPK and hMNPK treatments. The free particulate fraction represents the more recent organic amendment [35], the occluded particulate fraction within aggregates is also released [36], and the latter is chemically and physically distinct from the former [37] and will thus behave slightly differently in response to management. The long-term application of mineral fertilizers and organic amendment significantly increased the mineral-associated fraction $\mathrm{OC}$ and $\mathrm{N}$ concentrations, which constituted $65 \%-89 \%$ of the TOC concentration and $57 \%$ - 76\% of the TN concentration in this soil.

An increase in both the TOC and $\mathrm{N}$ concentrations in the aggregation fractions ( $>0.25 \mathrm{~mm}$ and $0.05-0.25 \mathrm{~mm}$ in size) was also affected by long-term fertilization, and these values were greater when fully-fermented soybean cake was added to the soil. These results agree with previous research reporting an increase in the OC of aggregate fractions under organic amendment [32] [38]. The combined application of mineral fertilizers along with organic amendment might provide all of the essential primary elements $(\mathrm{N}, \mathrm{P}$, and $\mathrm{K}$ ) that could enhance the total biomass yield; thus, more crop roots and stubble are added to the soil. The roots, hyphae, and decomposition products, such as polysaccharides, form aggregates that in return physically protect the TOC from microbial decomposition by engendering a physical barrier between the substrates and microbes. In this process, the crop roots, hyphae, and polysaccharides resulting from the decomposition of OM bind mineral particles into microaggregates, and then large numbers of microaggregates bind to form $\mathrm{C}$-rich macroaggregates. Macroaggregates accumulate higher levels of OC that could be due to the lower decomposition of SOM associated with macroaggregates. The aggregate fractions under the mineral fertilizers with organic amendment showed higher OC and $\mathrm{N}$ concentrations. For all treatments, the water-stable aggregate-associated fraction OC concentrations accounted for a very small proportion of the TOC, with little contribution to the TOC increase in this Vertisol. This implies that it is difficult to promote soil aggregation processes and OC protection in this type of soil, despite the addition of organic amendment, and the reason may be related to the local climate and soil conditions that contribute to the mineralization and decomposition of SOC.

\section{Conclusion}

Thirty-three years after organic amendment, we found that soil $\mathrm{OC}$ and $\mathrm{N}$ in- 
creased by $14 \%$ - $37 \%$ and $15 \%$ - 31\%, respectively, especially under the combination of mineral fertilizer with organic amendment as high $\mathrm{N}$ rate (hMNPK). This is mainly due to massive increases in the recalcitrant mineral-associated and coarse mineral-associated fractions. Fertilization increased the $\mathrm{C}$ concentration in the free particulate fraction but contributed less to increasing the TOC. The $\mathrm{C}$ and $\mathrm{N}$ added to soil by organic amendment were stored in mineral-associated fractions, and the effect of organic amendment was more obvious.

\section{Acknowledgements}

This study was supported in part by National Key Research and Development Program (Grant No. 2016YFD0300809), National Nature Science Foundation of China (Grant No. 41401244), Nature Science Foundation of Anhui Province (Grant No. 1608085MD87) and Climate Change Specific Project of China Meteorological Administration (Grant No. CCSF201616).

\section{References}

[1] Lal, R. (2011) Sequestering Carbon in Soils of Agro-Ecosystems. Food Policy, 36, S33-S39. https://doi.org/10.1016/j.foodpol.2010.12.001

[2] Kong, X., Lal, R., Li, B. and Li, K. (2014) Crop Yield Response to Soil Organic Carbon Stock over Long-Term Fertilizer Management in Huang-Huai-Hai Plains of China. Agricultural Research, 3, 246-256. https://doi.org/10.1007/s40003-014-0118-6

[3] Brady, N. and Weil, R. (1996) The Nature and Properties of Soils. Pearson Education, Inc., Upper Saddle River.

[4] Powlson, D.S., Bhogal, A., Chambers, B.J., Coleman, K., Macdonald, A.J., Goulding, K.W.T., et al. (2012) The Potential to Increase Soil Carbon Stocks through Reduced Tillage or Organic Material Additions in England and Wales: A Case Study. Agriculture, Ecosystems \& Environment, 146, 23-33. https://doi.org/10.1016/j.agee.2011.10.004

[5] Mariaselvam, A.A., Dandeniya, W.S., Indraratne, S.P. and Dharmakeerthi, R.S. (2015) High C/N Materials Mixed with Cattle Manure as Organic Amendments to Improve Soil Productivity and Nutrient Availability. Tropical Agricultural Research, 25, 201. https://doi.org/10.4038/tar.v25i2.8142

[6] Christensen, B.T. (1986) Straw Incorporation and Soil Organic Matter in Macro-Aggregates and Particle Size Separates. Journal of Soil Science, 37, 125-135. https://doi.org/10.1111/j.1365-2389.1986.tb00013.x

[7] von Lützow, M., Kögel-Knabner, I., Ekschmitt, K., Flessa, H., Guggenberger, G., Matzner, E., et al. (2007) SOM Fractionation Methods: Relevance to Functional Pools and to Stabilization Mechanisms. Soil Biology and Biochemistry, 39, 2183-2207. https://doi.org/10.1016/j.soilbio.2007.03.007

[8] Marriott, E.E. and Wander, M. (2006) Qualitative and Quantitative Differences in Particulate Organic Matter Fractions in Organic and Conventional Farming Systems. Soil Biology and Biochemistry, 38, 1527-1536. https://doi.org/10.1016/j.soilbio.2005.11.009

[9] Gosling, P., Parsons, N. and Bending, G.D. (2013) What Are the Primary Factors Controlling the Light Fraction and Particulate Soil Organic Matter Content of Agricultural Soils? Biology and Fertility of Soils, 49, 1001-1014. 
https://doi.org/10.1007/s00374-013-0791-9

[10] Schmidt, M.W.I., Torn, M.S., Abiven, S., Dittmar, T., Guggenberger, G., Janssens, I.A., et al. (2011) Persistence of Soil Organic Matter as an Ecosystem Property. Nature, 478, 49-56. https://doi.org/10.1038/nature10386

[11] Blanco-Moure, N., Gracia, R., Bielsa, A.C. and López, M.V. (2016) Soil Organic Matter Fractions as Affected by Tillage and Soil Texture under Semiarid Mediterranean Conditions. Soil and Tillage Research, 155, 381-389. https://doi.org/10.1016/j.still.2015.08.011

[12] Wani, S.P., Pathak, P., Jangawad, L.S., Eswaran, H. and Singh, P. (2003) Improved Management of Vertisols in the Semiarid Tropics for Increased Productivity and Soil Carbon Sequestration. Soil Use and Management, 19, 217-222. https://doi.org/10.1111/j.1475-2743.2003.tb00307.x

[13] Chan, K.Y. (1996) Consequences of Changes in Particulate Organic Carbon in Vertisols under Pasture and Cropping. Soil Science Society of America Journal, 61, 1376-1382. https://doi.org/10.2136/sssaj1997.03615995006100050013x

[14] Hua, K., Wang, D. and Guo, Z. (2017) Soil Organic Carbon Contents as a Result of Various Organic Amendments to a Vertisol. Nutrient Cycling in Agroecosystems, 108, 135-148. https://doi.org/10.1007/s10705-017-9845-y

[15] Guo, Z., Hua, K., Wang, J., Guo, X., He, C., et al. (2014) Effects of Different Regimes of Fertilization on Soil Organic Matter under Conventional Tillage. Spanish Journal of Agricultural Research, 12, 801-808. https://doi.org/10.5424/sjar/2014123-4859

[16] Zhang, M. and Gong, Z. (1992) Distribution, Characteristics and Taxonomic Classification of Vertisols in China. Acta Pedologica Sinica, 29, 1-17.

[17] Zhou, J. and Shen, R. (2013) Dictionary of Soil Science. Science Press, Beijing.

[18] Hua, K., Wang, D., Guo, X. and Guo, Z. (2014) Carbon Sequestration Efficiency of Organic Amendments in a Long-Term Experiment on a Vertisol in Huang-Huai-Hai Plain, China. PLOS ONE, 9, e108594. https://doi.org/10.1371/journal.pone.0108594

[19] Hai, L., Li, X.G., Li, F.M., Suo, D.R. and Guggenberger, G. (2010) Long-Term Fertilization and Manuring Effects on Physically-Separated Soil Organic Matter Pools under a Wheat-Wheat-Maize Cropping System in an Arid Region of China. Soil Biology and Biochemistry, 42, 253-259. https://doi.org/10.1016/j.soilbio.2009.10.023

[20] Elliott, E.T. (1986) Aggregate Structure and Carbon, Nitrogen, and Phosphorus in Native and Cultivated Soils. Soil Science Society of America Journal, 50, 627-633. https://doi.org/10.2136/sssaj1986.03615995005000030017x

[21] Lu, R.K. (2000) Analysis Method of Soil Agricultural Chemistry. China Agricultural Science and Technology Press, Beijing.

[22] Ding, X., Yuan, Y., Liang, Y., Li, L. and Han, X. (2014) Impact of Long-Term Application of Manure, Crop Residue, and Mineral Fertilizer on Organic Carbon Pools and Crop Yields in a Mollisol. Journal of Soils and Sediments, 14, 854-859. https://doi.org/10.1007/s11368-013-0840-x

[23] Hati, K.M., Swarup, A., Dwivedi, A.K., Misra, A.K. and Bandyopadhyay, K.K. (2007) Changes in Soil Physical Properties and Organic Carbon Status at the Topsoil Horizon of a Vertisol of Central India after 28 Years of Continuous Cropping, Fertilization and Manuring. Agriculture, Ecosystems \& Environment, 119, 127-134. https://doi.org/10.1016/j.agee.2006.06.017

[24] Yan, D., Wang, D. and Yang, L. (2007) Long-Term Effect of Chemical Fertilizer, Straw, and Manure on Labile Organic Matter Fractions in a Paddy Soil. Biology and Fertility of Soils, 44, 93-101. https://doi.org/10.1007/s00374-007-0183-0 
[25] Mikha, M.M., Hergert, G.W., Benjamin, J.G., Jabro, J.D. and Nielsen, R.A. (2015) Long-Term Manure Impacts on Soil Aggregates and Aggregate-Associated Carbon and Nitrogen. Soil Science Society of America Journal, 79, 626-636. https://doi.org/10.2136/sssaj2014.09.0348

[26] Smith, P., Powlson, D., Glendining, M. and Smith, J.O. (1997) Potential for Carbon Sequestration in European Soils: Preliminary Estimates for Five Scenarios using Results from Long-Term Experiments. Global Change Biology, 3, 67-79. https://doi.org/10.1046/j.1365-2486.1997.00055.x

[27] Muñoz-Romero, V., Lopez-Bellido, R.J., Fernandez-Garcia, P., Redondo, R., Murillo, S., et al. (2017) Effects of Tillage, Crop Rotation and N Application Rate on Labile and Recalcitrant Soil Carbon in a Mediterranean Vertisol. Soil and Tillage Research, 169, 118-123. https://doi.org/10.1016/j.still.2017.02.004

[28] Liu, E., Yan, C., Mei, X., Zhang, Y. and Fan, T. (2013) Long-Term Effect of Manure and Fertilizer on Soil Organic Carbon Pools in Dryland Farming in Northwest China. PLoS ONE, 8, e56536. https://doi.org/10.1371/journal.pone.0056536

[29] Gregorich, E.G., Liang, B.C., Ellert, B.H. and Drury, C.F. (1996) Fertilization Effects on Soil Organic Matter Turnover and Corn Residue C Storage. Soil Science Society of America Journal, 60, 472-476. https://doi.org/10.2136/sssaj1996.03615995006000020019x

[30] Zhang, W., Xu, M., Wang, B. and Wang, X. (2009) Soil Organic Carbon, Total Nitrogen and Grain Yields under Long-Term Fertilizations in the Upland Red Soil of Southern China. Nutrient Cycling in Agroecosystems, 84, 59-69. https://doi.org/10.1007/s10705-008-9226-7

[31] Sekhon, K.S., Singh, J.P. and Mehla, D.S. (2011) Long-Term Effect of Manure and Mineral Fertilizer Application on the Distribution of Organic Nitrogen Fractions in Soil under a Rice-Wheat Cropping System. Archives of Agronomy and Soil Science, 57, 705-714. https://doi.org/10.1080/03650340.2010.489555

[32] He, Y.T., Zhang, W.J., Xu, M.G., Tong, X.G., Sun, F.X., et al. (2015) Long-Term Combined Chemical and Manure Fertilizations Increase Soil Organic Carbon and Total Nitrogen in Aggregate Fractions at Three Typical Cropland Soils in China. Science of the Total Environment, 532, 635-644. https://doi.org/10.1016/j.scitotenv.2015.06.011

[33] Hu, C., Li, S.-L., Qiao, Y.A.N., Liu, D.-H. and Chen, Y.-F. (2015) Effects of 30 Years Repeated Fertilizer Applications on Soil Properties, Microbes and Crop Yields in Rice-Wheat Cropping Systems. Experimental Agriculture, 51, 355-369. https://doi.org/10.1017/S0014479714000350

[34] Alvarez, C.R., Alvarez, R., Grigera, M.S. and Lavado, R.S. (1998) Associations between Organic Matter Fractions and the Active Soil Microbial Biomass. Soil Biology and Biochemistry, 30, 767-773. https://doi.org/10.1016/S0038-0717(97)00168-5

[35] Wander, M.M. and Yang, X. (2000) Influence of Tillage on the Dynamics of Looseand Occluded-Particulate and Humified Organic Matter Fractions. Soil Biology and Biochemistry, 32, 1151-1160. https://doi.org/10.1016/S0038-0717(00)00031-6

[36] Sohi, S.P., Mahieu, N., Arah, J.R.M., Powlson, D.S., Madari, B. and Gaunt, J.L. (2001) A Procedure for Isolating Soil Organic Matter Fractions Suitable for Modeling. Soil Science Society of America Journal, 65, 1121-1128. https://doi.org/10.2136/sssaj2001.6541121x

[37] Kölbl, A., Leifeld, J. and Kögel-Knabner, I. (2005) A Comparison of Two Methods for the Isolation of Free and Occluded Particulate Organic Matter. Journal of Plant Nutrition and Soil Science, 168, 660-667. https://doi.org/10.1002/jpln.200521805 
[38] Yu, H., Ding, W., Luo, J., Geng, R. and Cai, Z. (2012) Long-Term Application of Organic Manure and Mineral Fertilizers on Aggregation and Aggregate-Associate Carbon in a Sandy Loam Soil. Soil and Tillage Research, 124, 170-177.

https://doi.org/10.1016/j.still.2012.06.011 